\title{
Clinical characteristics and outcome of tumor-associated acute pancreatitis: a single-center cohort study
}

\author{
Yangyang Xiong', Yi Zhao ${ }^{1}$, Xianlin Han ${ }^{2}$, Guorong Chen ${ }^{1}$, John Windsor ${ }^{3}$, Dong Wu ${ }^{1,4}$, Jiaming Qian ${ }^{1}$ \\ ${ }^{1}$ Department of Gastroenterology, State Key Laboratory of Complex Severe and Rare Diseases, Peking Union Medical College Hospital, Peking \\ Union Medical College, Chinese Academy of Medical Sciences, Beijing, China; ${ }^{2}$ Department of General Surgery, Peking Union Medical College \\ Hospital, Peking Union Medical College, Chinese Academy of Medical Sciences, Beijing, China; ${ }^{3}$ Surgical and Translational Research Center, \\ Faculty of Medical and Health Sciences, The University of Auckland, Park Road, Auckland, New Zealand; ${ }^{4}$ Clinical Epidemiology Unit, Peking \\ Union Medical College Hospital, Peking Union Medical College, Chinese Academy of Medical Sciences, Beijing, China \\ Contributions: (I) Conception and design: Y Xiong, D Wu, J Qian; (II) Administrative support: X Han, J Windsor, D Wu, J Qian; (III) Provision \\ of study materials or patients: X Han, D Wu, J Qian; (IV) Collection and assembly of data: Y Xiong, Y Zhao, G Chen; (V) Data analysis and \\ interpretation: Y Xiong, Y Zhao; (VI) Manuscript writing: All authors; (VII) Final approval of manuscript: All authors. \\ Correspondence to: Professor Dong Wu. Department of Gastroenterology, State Key Laboratory of Complex Severe and Rare Diseases Clinical \\ Epidemiology Unit, Peking Union Medical College Hospital, Peking Union Medical College, Chinese Academy of Medical Sciences. No. 1 \\ Shuaifuyuan, Dongcheng District, Beijing 100730, China. Email: wudong@pumch.cn; Professor Jiaming Qian. Department of Gastroenterology, \\ State Key Laboratory of Complex Severe and Rare Diseases, Peking Union Medical College Hospital, Peking Union Medical College, Chinese \\ Academy of Medical Sciences. No. 1 Shuaifuyuan, Dongcheng District, Beijing 100730, China. Email: qianjiaming1957@126.com.
}

Background: What features should alert clinicians to suspect underlying tumors in patients with acute pancreatitis (AP) was largely unknown. This study aimed to assess the clinical characteristics and outcome in patients with tumor-associated AP.

Methods: Patients who presented with AP and were diagnosed with tumor after admission were included according to the inclusion and exclusion criteria and followed up by hospital notes, telephone, WeChat and/ or e-mail. The clinical characteristics and outcome were analyzed with multivariable logistic regression and were compared with AP patients without tumor.

Results: Out of a cohort of 1,792 AP patients we identified 103 who had a neoplastic etiology. The 103 patients had a median age of 57 (range, 13-81) and 65 were males. AP was mild in 92 patients, moderately severe in 7 and severe in 4. The three most common tumors included pancreatic cancer (PC) (40), periampullary carcinoma (PAC) (25), and neoplastic pancreatic cysts (NPC) (22). The following ranked features were predictive of a tumor etiology: dilation of main pancreatic duct (MPD) (OR 417.83, 95\% CI: 80.402,171.42), vascular invasion (OR 82.04, 95\% CI: 6.05-1,113.14), mild AP (8.29, 95\% CI: 1.98-34.73), and anemia (OR 5.73, 95\% CI: 2.02-16.26). The median survival period of AP patients with PC, PAC, and NPC was 10.0 (7.0-23.5), 21.0 (5.0-37.0), and 35.0 (30.0-96.0) months, respectively.

Conclusions: Mild AP patients with dilation of MPD, vascular invasion, and anemia were more frequently suggested a tumor etiology. Thus, clinical vigilance is needed for timely detection of tumor-associated pancreatitis with these characteristics.

Keywords: Acute pancreatitis (AP); tumor; retrospective study

Submitted Oct 29, 2020. Accepted for publication Jan 29, 2021.

doi: 10.21037/atm-20-7196

View this article at: http://dx.doi.org/10.21037/atm-20-7196 


\section{Introduction}

Acute pancreatitis (AP), an inflammatory disorder of the pancreas, is the leading cause for acute admission among gastrointestinal disorders worldwide (1). The etiology of $\mathrm{AP}$ is complex and about $10 \%$ of patients are idiopathic with the exclusion of all the common causes (2). Followup of these cases may lead to tumors and it was reported that AP might be an early manifestation of many types of tumors, including pancreatic cancer, ampullary carcinoma, intraductal papillary mucinous neoplasms (IPMN), nonHodgkin lymphoma (NHL), metastatic lung cancer, and parathyroid carcinoma (3-8). Disappointingly, most were case reports, and there was a lack of data regarding typical presentations and diagnostic clues (such as elderly, mild AP) in the early stage of those tumors. While AP might, if appropriately investigated, lead to the earlier diagnosis and better outcome of a pancreatic tumor, it can also result in a delay in diagnosis if clinicians are less vigilant. Any delays, especially for pancreatic adenocarcinoma cases, can adversely impact survival, resulting in late stage of tumor, poor quality of life and short survival time, etc. (9).

This study aimed to analyse a single-center experience with the management of tumor-associated acute pancreatitis, with a particular focus on clinical characteristics and outcome. We presented the following article in accordance with the STROBE reporting checklist (available at http:// dx.doi.org/10.21037/atm-20-7196).

\section{Methods}

\section{Patients and settings}

We retrospectively reviewed the electronic medical records of patients with a tumor who presented with AP as the primary admission diagnosis at Peking Union Medical College Hospital in Beijing, China, from 1 January 2000 to 1 December 2018. Eligible patients had the discharge diagnoses of both AP [ICD 10 code (K85)] and tumor [ICD 10 code (C00)-(D48)]. Inclusion criteria: patients had to present with AP and the diagnosis of tumor was made after the onset of AP. The diagnosis of AP was based on the American College of Gastroenterology guidelines (10), which should fulfil at least two of the following three criteria: (I) abdominal pain characteristic of AP, (II) serum lipase equal to or higher than three times the upper normal limit, and (III) characteristic findings of AP on radiologic exams. All the selected patients with tumors had histological confirmation from surgical specimens or fine needle biopsy.
Exclusion criteria were as follows: (I) patients diagnosed with tumors before the onset of AP, (II) patients with AP due to an alternative etiology (including gallstone, alcohol, hyperlipidemia, etc.), (III) patients with chronic pancreatitis, and (IV) patients who had missing data as outlined in the Variables section.

The included patients were followed up by various methods (including hospital notes, telephone, WeChat and/or e-mail) from date of tumor diagnosis until death, or 1 December 2019, depending on which occurred first. AP without tumor (controls) were selected from the AP database, which had been described elsewhere $(11,12)$, using stratified random sampling. Controls were matched to each study subject by gender and length of stay at a 1:4 ratio. The study was conducted in accordance with the Declaration of Helsinki (as revised in 2013). The present study was approved by the Institutional Committee of Ethics of Peking Union Medical College Hospital (S-K900), and individual consent for this retrospective analysis was waived.

\section{Measures and outcomes}

Demographic variables, including age, gender, medical history, alcohol, and tobacco consumption were abstracted. Clinical data included mortality, severity of AP, length of hospital stay, intensive care unit (ICU) admission, local complications, systematic complications, and laboratory data on admission. Acute Physiologic Assessment and Chronic Health Evaluation (APACHEII) was calculated $48 \mathrm{~h}$ after presentation. Haemoglobin (HGB) below $110 \mathrm{~g} / \mathrm{L}$ for female or $120 \mathrm{~g} / \mathrm{L}$ for male was defined as anemia (13). Main pancreatic duct (MPD) dilatation on CT was defined by an MPD with a maximal diameter greater than $3 \mathrm{~mm}$ (14). Vascular invasion on CT was defined as the fat disappeared between the mass and adjacent vessels, the mass wrapped around more than $180^{\circ}$ of the circumference of the adjacent vessels, and blood vessels were observed with stenosis (15). The database was set up and independently checked by two authors (Y Xiong and Y Zhao).

\section{Procedures}

The ICD code was adopted to retrieve patients diagnosed with AP [ICD 10 code (K85)] and tumor [ICD 10 code (C00)-(D48)] at Peking Union Medical College Hospital from 1 January 2000 to 1 December 2018. Eligible patients were selected based on the inclusion criteria and exclusion 
Table 1 General characteristics of patients with tumors $(n=103)$ presenting acute pancreatitis

\begin{tabular}{|c|c|}
\hline Characteristics & Outcome \\
\hline Age (years)* & $57[13-81]$ \\
\hline Sex (male) & $65(63.1 \%)$ \\
\hline $\mathrm{HCT}(\%)^{\dagger}$ & 36.9 (37.9) \\
\hline $\mathrm{Cr}(\mathrm{umol} / \mathrm{L})^{\dagger}$ & $74.8(68.0)$ \\
\hline $\mathrm{BUN}(\mathrm{mmol} / \mathrm{L})^{\dagger}$ & $4.9(4.4)$ \\
\hline \multicolumn{2}{|l|}{ Severity (RAC) } \\
\hline MAP & $92(89.3 \%)$ \\
\hline MSAP & $7(6.8 \%)$ \\
\hline SAP & $4(3.9 \%)$ \\
\hline \multicolumn{2}{|l|}{ Local complications } \\
\hline Acute peripancreatic fluid collection & $11(10.7 \%)$ \\
\hline Acute necrotic collection & $6(5.8 \%)$ \\
\hline Walled-off necrosis & 0 \\
\hline Infected necrosis & 0 \\
\hline Pancreatic pseudocysts & $6(5.8 \%)$ \\
\hline \multicolumn{2}{|l|}{ Organ failure } \\
\hline Multiple organ failure & $1(0.9 \%)$ \\
\hline Respiratory failure & $2(1.9 \%)$ \\
\hline Renal failure & $3(2.9 \%)$ \\
\hline Shock & 0 \\
\hline APACHE II $(48 \mathrm{~h})^{\dagger}$ & $4.8(3.7)$ \\
\hline Ranson $^{\dagger}$ & $0.9(0.8)$ \\
\hline SIRS & $5(4.9)$ \\
\hline ICU admission & $4(3.9)$ \\
\hline Length of stay (days)* & $18[2-60]$ \\
\hline Mortality due to AP & 0 \\
\hline Mortality due to tumor & $47(45.6 \%)$ \\
\hline
\end{tabular}

Values in parentheses are percentages unless indicated otherwise; ${ }^{*}$ values are median [range] and ${ }^{\dagger}$ values in mean (s.d.). RAC, Revised Atlanta Classification; MAP, mild AP; MSAP; moderately severe AP; SAP, severe AP; APACHE, Acute Physiologic Assessment and Chronic Health Evaluation; SIRS, systematic inflammatory response syndrome; ICU, intensive care unit.

criteria. We extracted clinical data from the hospital's electronic medical records and followed up the prognosis of tumor by hospital notes, telephone, WeChat and/or e-mail. Two persons established the database independently, and the inconsistencies were submitted to senior physicians for review and decision. The control group who were without tumor, was matched with contemporaneous patients with AP by 1:4 ratio who were randomly selected from the AP database which had been described elsewhere.

\section{Statistical analysis}

We performed analyses to describe and summarize the distributions of variables. We use the Student's $t$ test, Wilcoxon rank-sum test or Kruskal-Wallis test to compare continuous variables, and the Chi-square test or Fisher's exact test to compare categorical variables. Univariable and multivariable logistic regression analysis was then applied to identify clinical features for tumors. All statistical analysis was performed using SPSS ${ }^{\circledR}$ version 22 (IBM, Armonk, New York, USA). $\mathrm{P}$ values of $<0.05$ were considered to be statistically significant.

\section{Results}

Out of 1792 AP patients, we identified 103 with tumors who presented with AP as the admission diagnosis. All the tumors were diagnosed after admission with AP. The median age of the cohort was 57 (range, 13-81) years with 65 males. The main clinical characteristics of these patients were summarized in Table 1. Abdominal pain occurred in all 103 patients. Median weight loss was 6.5 (range, 2-30) kilograms in 82 patients and obstructive jaundice in 29. The severity grade of AP was mild in 92 patients, moderately severe in 7 and severe in 4. Smoking history was present in 21 patients and drinking history in 17 .

\section{Tumor types}

Of these 103 patients, the most common tumor is pancreatic cancer (PC) (40/103), followed by periampullary carcinoma (PAC) (25/103), neoplastic pancreatic cysts (NPC) (22/103), non-Hodgkin's lymphoma (5/103), metastatic lung cancer (4/103), parathyroidoma (3/103), pancreatic neuroendocrine tumor (pNET) (2/103), multiple myeloma (2/103).

Histopathologically, adenocarcinoma (38 cases) accounted for the majority of pancreatic cancer, the other one was carcinoma, and one was cystadenocarcinoma. As for periampullary carcinoma, 10 cases were vater ampulla carcinoma, 8 cases were cholangiocarcinoma, and 7 cases were duodenal adenocarcinoma. Neoplastic pancreatic cysts included 17 cases intraductal papillary mucinous neoplasms 
Table 2 Clinical characteristics of patients with different tumors

\begin{tabular}{|c|c|c|c|c|c|c|}
\hline & $\begin{array}{c}\text { Pancreatic } \\
\text { Cancer }(n=40)\end{array}$ & $\begin{array}{c}\text { Periampullary } \\
\text { carcinoma }(n=25)\end{array}$ & $\begin{array}{c}\text { Neoplastic pancreatic } \\
\text { cysts }(n=22)\end{array}$ & $\begin{array}{l}\text { Non- Hodgkin's } \\
\text { lymphoma }(n=5)\end{array}$ & $\begin{array}{l}\text { Metastatic lung } \\
\text { cancer }(n=4)\end{array}$ & $\mathrm{P}$ \\
\hline \multicolumn{7}{|l|}{ Demographic data } \\
\hline Age (years) ${ }^{*}$ & 56 [29-81] & 57 [33-80] & $62[13-79]$ & $41[25-66]$ & $61[57-66]$ & 0.236 \\
\hline Sex (male) & $24(60.0 \%)$ & $13(52.0 \%)$ & $19(86.4 \%)$ & $3(60.0 \%)$ & $4(100.0 \%)$ & 0.060 \\
\hline Radiation pain & $15(37.5 \%)$ & $6(24.0 \%)$ & $2(9.1 \%)$ & $1(20.0 \%)$ & $2(50.0 \%)$ & 0.095 \\
\hline Vomiting & $10(25.0 \%)$ & $12(48.0 \%)$ & 9 (40.9\%) & $2(40.0 \%)$ & $1(25.0 \%)$ & 0.377 \\
\hline Jaundice & $12(30.0 \%)$ & $14(56.0 \%)$ & $1(4.5 \%)$ & $1(20.0 \%)$ & $1(25.0 \%)$ & 0.003 \\
\hline Dilation of MPD & $30(75.0 \%)$ & $14(56.0 \%)$ & $17(77.3 \%)$ & $2(40.0 \%)$ & $1(25.0 \%)$ & 0.035 \\
\hline Dilation of BD & $19(47.5 \%)$ & $17(68.0 \%)$ & $1(4.5 \%)$ & $1(20.0 \%)$ & $1(25.0 \%)$ & $<0.001$ \\
\hline Vascular invasion & $20(50.0 \%)$ & $4(16.0 \%)$ & $3(13.6 \%)$ & $1(20.0 \%)$ & 0 & 0.004 \\
\hline Enlarged lymph glands & $4(10.0 \%)$ & 0 & 0 & $2(40.0 \%)$ & $1(25.0 \%)$ & 0.008 \\
\hline Pancreatic mass on US & $12(30.0 \%)$ & $1(4.0 \%)$ & $8(36.4 \%)$ & $1(20.0 \%)$ & 0 & 0.046 \\
\hline Pancreatic mass on CT & $34(85.0 \%)$ & $3(12.0 \%)$ & $16(72.7 \%)$ & $1(20.0 \%)$ & $4(100.0 \%)$ & $<0.001$ \\
\hline \multicolumn{7}{|l|}{ Admission bloods } \\
\hline \multicolumn{7}{|l|}{ Tumor markers } \\
\hline $\mathrm{CEA}(\mathrm{ng} / \mathrm{mL})^{\dagger}$ & $3.9(6.5)$ & $5.9(7.2)$ & $2.5(1.2)$ & NA & $3.8(1.7)$ & 0.491 \\
\hline CA 19-9 (u/mL $)^{\dagger}$ & $1,047.6(3,096.7)$ & $1,110.2(2,565.1)$ & $20.4(33.5)$ & NA & $38.3(22.0)$ & $<0.001$ \\
\hline
\end{tabular}

Values in parentheses are percentages unless indicated otherwise; *values are median [range] and ${ }^{\dagger}$ values in mean (s.d.). MPD, main pancreatic duct; BD: bile duct; US, ultrasonography; CT, computed tomography; CEA, carcinoembryonic antigen; CA, carbohydrate antigen; NA, not available.

(8 cases of invasive), 3 cases serous cystadenomas, and 2 cases solid-pseudopapillary neoplasms. Among the 5 cases of non-Hodgkin's lymphoma, 4 cases were diffuse large B lymphoma, 1 case was T-cell lymphoma. As for metastatic lung cancer, 4 cases were all small cell lung cancer.

\section{Clinical characteristics of patients with different tumors}

The clinical characteristics of AP patients with different tumors were summarized in Table 2. Besides, there were 18 patients with a dilated MPD and/or vascular invasion but 
Table 3 Clinical outcomes of patients with different tumors

\begin{tabular}{|c|c|c|c|c|c|c|}
\hline & $\begin{array}{c}\text { Pancreatic } \\
\text { Cancer }(n=40)\end{array}$ & $\begin{array}{c}\text { Periampullary } \\
\text { carcinoma }(n=25)\end{array}$ & $\begin{array}{l}\text { Neoplastic pancreatic } \\
\text { cysts }(n=22)\end{array}$ & $\begin{array}{l}\text { Non- Hodgkin's } \\
\text { lymphoma }(n=5)\end{array}$ & $\begin{array}{l}\text { Metastatic lung } \\
\text { cancer }(n=4)\end{array}$ & $P$ \\
\hline $\begin{array}{l}\text { Days from AP } \\
\text { onset to diagnosis } \\
\text { of tumor }\end{array}$ & 93 [11-489] & $41[4-946]$ & $426[8-3,324]$ & 29 [2-57] & 106 [99-112] & $<0.001$ \\
\hline AJCC stages & & & & & & $<0.001$ \\
\hline Stage II & $1(2.5 \%)$ & $9(36.0 \%)$ & 0 & $1(20.0 \%)$ & 0 & \\
\hline Stage III & $11(27.5 \%)$ & $5(20.0 \%)$ & 0 & $1(20.0 \%)$ & 0 & \\
\hline Stage IV & $10(25.0 \%)$ & $4(16.0 \%)$ & 0 & $3(60.0 \%)$ & $4(100.0 \%)$ & \\
\hline $\begin{array}{l}\text { Surgery } \\
\text { due to tumor }\end{array}$ & 27 (67.5\%) & $22(88.0 \%)$ & $18(81.8 \%)$ & $1(20.0 \%)$ & $1(25.0 \%)$ & 0.003 \\
\hline $\begin{array}{l}\text { Mortality due to } \\
\text { tumor }\end{array}$ & $25(62.5 \%)$ & $11(44.0 \%)$ & $1(4.5 \%)$ & $4(80.0 \%)$ & $3(75.0 \%)$ & $<0.001$ \\
\hline Survival (months) $)^{\ddagger}$ & $10.0(7.0-23.5)$ & $21.0(5.0-37.0)$ & $35.0(30.0-96.0)$ & $8.5(2.0-36.0)$ & $8.5(5.3-15.5)$ & $<0.001$ \\
\hline
\end{tabular}

without a mass reported by computed tomography (CT). As for pancreatic cancer, the detection rates of mass by CT were $17.6 \%, 29.4 \%, 38.2 \%, 55.9 \%$ and $70.6 \%$ at the 1 st week, $2^{\text {nd }}$ week, $4^{\text {th }}$ week, $8^{\text {th }}$ week, and $12^{\text {th }}$ week from the onset of AP, respectively.

In addition, three patients were diagnosed with functional parathyroid adenoma (PTH 193-629 pmol/L) and two with multiple myeloma. AP was caused by hypercalcemia (2.72$4.89 \mathrm{mmol} / \mathrm{L}$ ) in all the five patients, including two cases of severe acute pancreatitis. There were two cases of pNET, of which the symptoms were not specific, mainly presented as abdominal pain, vomiting and pancreatic mass on CT.

\section{Clinical outcome of patients with different tumors}

The clinical outcome of patients with tumor-associated acute pancreatitis were summarized in Table 3. The median survival time of AP patients with PC was 10.0 (7.0-23.5) months. All patients with parathyroidoma recovered after surgical resection of the adenoma. These patients were followed up for up to 3 years or more, and no AP recurred. Patients with multiple myeloma received chemotherapy, and both of them died (survival time was 1 month and
13 months, respectively). Of these two pNET patients, one improved after surgery, while the other died in 27 months due to disease progression.

\section{Diagnostic clues for patients with different tumors presenting acute pancreatitis}

Due to the heterogeneity among tumors, we took the primary abdominal tumors (pancreatic cancer PC, periampullary carcinoma PAC, and neoplastic pancreatic cysts NPC) as a tumor group, which accounted for the largest proportion $(87,84.5 \%)$, to compare with the control group that patients having AP without tumor (Table 4).

The incidence of MSAP, SAP, organ failure, ICU admission, and APACHE II score were lower in the tumor group $(\mathrm{P}<0.05)$. The per cent of age above 50 , weight loss, anemia, dilation of main pancreatic duct (MPD), and vascular invasion in the tumor group were higher than in the control group $(\mathrm{P}<0.05)$.

Multivariable logistic regression analysis revealed that patients with dilation of MPD (OR 417.83, 95\% CI: 80.402,171.42, $\mathrm{P}<0.001)$, vascular invasion (OR 82.04, 95\% CI: 6.05-1,113.14, P=0.001), mild AP (OR 8.29, 95\% CI: 1.98 
Table 4 Comparison of clinical characteristics between AP patients with and without tumors (matched by 1:4 ratio)

\begin{tabular}{|c|c|c|c|}
\hline & $\begin{array}{l}\text { AP with tumor } \\
\qquad(\mathrm{n}=87)\end{array}$ & $\begin{array}{l}\text { AP without tumor } \\
\qquad(\mathrm{n}=348)\end{array}$ & $P$ \\
\hline Age (years) & & & $<0.001$ \\
\hline$\leq 50$ & $18(20.7)$ & 168 (48.3) & \\
\hline$>50$ & 69 (79.3) & $180(51.7)$ & \\
\hline Sex (male) & $56(64.4 \%)$ & $221(63.5 \%)$ & 0.881 \\
\hline Jaundice & $27(31.0 \%)$ & $126(36.2 \%)$ & 0.366 \\
\hline Fever & $13(14.9 \%)$ & $53(15.2 \%)$ & 0.947 \\
\hline Weight loss & $70(80.5 \%)$ & $13(3.7 \%)$ & $<0.001$ \\
\hline Anemia & $20(23.0 \%)$ & $29(8.3 \%)$ & $<0.001$ \\
\hline $\mathrm{Cr}(\mu \mathrm{mol} / \mathrm{L})^{\dagger}$ & $68.7(18.5)$ & $106.8(87.8)$ & $<0.001$ \\
\hline $\mathrm{BUN}(\mathrm{mmol} / \mathrm{L})^{\dagger}$ & $4.8(1.9)$ & $6.0(4.0)$ & 0.008 \\
\hline Dilation of MPD & $61(70.9 \%)$ & $2(0.6 \%)$ & $<0.001$ \\
\hline Vascular invasion & 27 (31.0\%) & $1(0.3 \%)$ & $<0.001$ \\
\hline Severity(RAC) & & & $<0.001$ \\
\hline MAP & $80(92.0 \%)$ & $206(59.2 \%)$ & \\
\hline MSAP & $6(6.9 \%)$ & $73(21.0 \%)$ & \\
\hline SAP & $1(1.1 \%)$ & $69(19.8 \%)$ & \\
\hline Local complications & $19(21.8 \%)$ & $70(20.1 \%)$ & 0.721 \\
\hline Organ failure & $1(1.1 \%)$ & $74(21.3 \%)$ & $<0.001$ \\
\hline APACHE II (48h) ${ }^{\dagger}$ & $4.2(2.3)$ & $5.7(5.3)$ & 0.010 \\
\hline Length of stay (days) ${ }^{\star}$ & 19 [2-60] & $18[1-134]$ & 0.386 \\
\hline ICU admission & $1(1.1 \%)$ & $49(14.1 \%)$ & 0.001 \\
\hline $\begin{array}{l}\text { Mortality due to } \\
\text { pancreatitis }\end{array}$ & 0 & $10(2.9 \%)$ & 0.195 \\
\hline
\end{tabular}

Values in parentheses are percentages unless indicated otherwise; *values are median [range] and ${ }^{\dagger}$ values in mean (s.d.). Abbreviations: MPD, main pancreatic duct; RAC, Revised Atlanta Classification; MAP, mild AP; MSAP; moderately severe AP; SAP, severe AP; APACHE, Acute Physiologic Assessment and Chronic Health Evaluation; ICU, intensive care unit.

34.73, $\mathrm{P}=0.004)$, and anemia (OR 5.73, 95\% CI: 2.02-16.26, $\mathrm{P}=0.001)$ were independently associated with the presence of a tumor (Table 5$)$.

\section{Discussion}

This study had identified four variables in patients presenting with AP that were independently associated with
Table 5 Factors independently associated with tumor pre-existing acute pancreatitis: Multivariable logistic regression analysis

\begin{tabular}{lcccc}
\hline Variable & Wald & OR & $95 \% \mathrm{Cl}$ & $\mathrm{P}$ \\
\hline Dilation of MPD & 51.32 & 417.83 & $80.40-2,171.42$ & $<0.001$ \\
vascular invasion & 10.97 & 82.04 & $6.05-1,113.14$ & 0.001 \\
Mild AP & 8.38 & 8.29 & $1.98-34.73$ & 0.004 \\
Anemia & 10.75 & 5.73 & $2.02-16.26$ & 0.001 \\
\hline MPD, main pancreatic duct; Cl, confidence interval; OR, odds \\
ratio.
\end{tabular}

a tumorous etiology: dilatation of the main pancreatic duct, vascular invasion, mild AP, and anemia. These variables represent clues for the diagnosis of tumor-associated AP. Moreover, it showed that AP can be an early presenting sign of a series of tumors even before the tumor itself is diagnosed, and if AP had been appropriately investigated, it might result in an earlier diagnosis of tumor. When compared to patients with AP but without tumor, we found that the severity of AP in the tumor group was more likely to be mild, which was similar to the study by Yohei Minato and Terumi Kamisawa (16).

The factors that should alert the clinician to suspect underlying tumors in patients who present with $\mathrm{AP}$ was largely unknown. In a previous study by Mujica and Barkin, patients with $\mathrm{PC}$ who presented with AP were generally older than 50 years of age and $89 \%$ was mild AP (17). Tanasijtchouk et al. (18) suggested that recurrent pancreatitis without identifiable cause, particularly in elderly patients accompanied by elevated bilirubin, should raise the suspicion of periampullary tumors. Jang et al. (5) reported that AP caused by IPMN was more likely to be mild. Several other authors had described acute pancreatitis as a reporting sign of pancreatic neuroendocrine tumor (pNET), non-Hodgkin's lymphoma (NHL), lung cancer, parathyroidoma, and multiple myeloma in case reports $(4,7,8,19,20)$. But these studies did not include patients with a whole range of neoplastic causes and did not compare $\mathrm{AP}$ patients with and without the presence of a tumor. In the present study, we found that pancreatic cancer (PC), periampullary carcinoma (PAC), neoplastic pancreatic cysts (NPC) were the most common causes for tumor-associated AP, which accounted for more than $80 \%$ in this cohort, followed by non-Hodgkin's lymphoma (NHL), lung cancer, parathyroidoma, pancreatic neuroendocrine tumor (pNET), and multiple myeloma.

It was worth noting that diagnostic delay was common in 
our cohort, taking an average of 93 days from the onset of AP to detect pancreatic cancer. There are Several reasons could account for the delay. First of all, it was well known that abdominal ultrasonography was suboptimal as the initial radiologic assessment for pancreatic tumors, for it was less sensitive and highly operator-dependent. Another possible explanation was that physicians tended to accept a common etiology (premature closure), such as gallstones or alcohol, rather than to search for a preexisting tumor, due to the lack of specific characteristics in the early stage of these tumors $(2,10)$. Finally, the use of CT, especially contrast-enhanced CT, was not a routine diagnostic workup for AP patients, particularly in mild cases. Even if applied, diffuse pancreatic inflammation can mask a localized mass in the acute setting $(21,22)$. Cho et al. argued that AP patients who had no clear etiology should routinely receive CT within three months after discharge in order to reveal underlying tumor (23). In our study, the overall sensitivity of CT in detecting pancreatic tumor was $85 \%$, which was significantly higher than that of ultrasonography $(30 \%)$. The detection rates by CT were $17.6 \%, 29.4 \%, 38.2 \%$, $55.9 \%$ and $70.6 \%$ at week $1,2,4,8$, and 12 from the onset of AP, respectively. Our data supported conclusions by other authors that those idiopathic AP patients should be closely followed after discharge to avoid missed diagnosis of pancreatic tumors. If possible, such investigations should be performed after an interval of 3 to 4 weeks or scheduled follow-up at least within three months after discharge to allow for resolution of inflammatory changes secondary to the pancreatitis episode (23). Furthermore, we noted that in the present study, about one third of patients with PC remained undetectable in three months after discharge. Our finding justified a longer period of follow-up (six months to one year) particularly for those high-risk patients presented with older age, dilated pancreatic duct, anemia, and vascular abnormalities.

Acute pancreatitis had been previously reported as a favorable prognostic indicator in patients with tumors $(24,25)$. A plausible explanation was that without AP these patients would have been easily overlooked due to no specific symptoms. And if AP had been appropriately investigated, it might result in an earlier diagnosis and, as a consequence, a better outcome (9). In a large national retrospective cohort study, Kirkegard et al. (25) investigated 12,522 patients with PC in Denmark and 37,522 patients in the United States (US) over a 13-year period. These patients were divided into two groups, cases with AP before PC and those without AP (179 vs. 12,343 cases in Denmark,
2,207 vs. 35,345 cases in the US). In the Danish cohort, the proportion of low-grade PC was higher (24.6\% vs. $14.7 \%$ ) in the AP group than the control group, surgical resection rate was also higher (20.1\% vs. $12.1 \%)$, and the survival period longer (6.9 vs. 3.9 months). In the US cohort, the proportion of low-grade PC was higher (38.9\% vs. $28.8 \%$ ) in the AP group than the control group, but the ratio of surgical resection ( $16.1 \%$ vs. $11.3 \%$ ) and the survival period ( 3.9 vs. 3.8 months) were comparable between the two groups. In our study, the median survival of PC patients was 10.0 months, which was significantly higher than PC patients without AP in the Danish and US cohort [10.0 (7.0-23.5) vs. 3.9 (1.3-10.8) months, $\mathrm{P}<0.001,10.0$ (7.0$23.5)$ vs. 3.8 (1.3-9.8) months, $\mathrm{P}<0.001$, respectively], and was even higher than $\mathrm{PC}$ patients with $\mathrm{AP}$ in the two cohorts [10.0 (7.0-23.5) vs. 6.9 (2.0-15.3) months, $\mathrm{P}<0.001,10.0$ (7.0-23.5) vs. 3.9 (1.3-11.0) months, $\mathrm{P}<0.001$, respectively] (25). It may be attributed to a high proportion of low-grade PC and a high surgical resection rate in our patients.

The underlying mechanisms of tumor-associated AP were unclear. There were several pathogenetic hypotheses: (I) mechanical obstruction of the pancreatic duct due to the mass, lymphadenopathy or poor pancreatic juice drainage, (II) pancreatic ischemia caused by vascular compromise secondary to tumor invasion, (III) secondary to hypercalcemia caused by tumor $(4,5,19)$. In a series of 66 patients, $75.8 \%$ had pancreatic neoplasms and almost $40 \%$ of these patients had obstruction of the MPD (26). In our study, more than two thirds of patients had dilated pancreatic duct, approximately a quarter of patients had vascular infiltration, and less than one tenth had peripancreatic lymphadenopathy or hypercalcemia, which was consistent with previous reports. We postulated that as tumor-associated AP was mainly the consequence of mass effect, which usually developed over months or even years, it was not surprising that most $\mathrm{AP}$ episodes in these patients were mild and self-limited. But when AP was caused by hypercalcemia, it could be severe as seen in one patient with parathyroidoma and the other with multiple myeloma in our cohort.

The major strengths of our study included a reasonable sample size comprising different types of tumors, and we used a matched control group to identify the reporting signs and diagnostic clues for pre-existing tumors. Limitations of the study must be noted. First, it was a single-center retrospective study so we expected that our findings could be validated in other studies. Second, different tumors had variable clinical manifestations and pathogenesis, making it 
difficult to elaborate and compare the characteristics among all types of tumors. Last but not least, the retrospective nature of this study made a certain survival bias inevitable. Needless to say that future multi-center prospective studies were eagerly awaited to address these limitations.

In summary, our study highlighted the need of improved diagnostic workup and regular follow-up in high-risk patients, such as age above 50, without identifiable causes, with mild AP, anemia, dilation of MPD, and vascular invasion, in whom timely surveillance was crucial to reveal the underlying tumor.

\section{Acknowledgments}

Funding: This work was supported by Beijing Natural Science Foundation (No. 7192162) and Chinese Academy of Medical Sciences (2019XK320036).

\section{Footnote}

Reporting Checklist: The authors have completed the STROBE reporting checklist. Available at http://dx.doi. org/10.21037/atm-20-7196

Data Sharing Statement: Available at http://dx.doi. org/10.21037/atm-20-7196

Peer Review File: Available at http://dx.doi.org/10.21037/ atm-20-7196

Conflicts of Interest: All authors have completed the ICMJE uniform disclosure form (available at http://dx.doi. org/10.21037/atm-20-7196). The authors have no conflicts of interest to declare.

Ethicsal Statement: The authors were accountable for all aspects of the work in ensuring that questions related to the accuracy or integrity of any part of the work were appropriately investigated and resolved. The study was conducted in accordance with the Declaration of Helsinki (as revised in 2013). The study protocol was reviewed and approved by the Institutional Committee of Ethics of Peking Union Medical College Hospital (S-K900), and individual consent for this retrospective analysis was waived.

Open Access Statement: This is an Open Access article distributed in accordance with the Creative Commons Attribution-NonCommercial-NoDerivs 4.0 International
License (CC BY-NC-ND 4.0), which permits the noncommercial replication and distribution of the article with the strict proviso that no changes or edits are made and the original work is properly cited (including links to both the formal publication through the relevant DOI and the license). See: https://creativecommons.org/licenses/by-nc-nd/4.0/.

\section{References}

1. Gapp J, Hall AG, Walters RW, et al. Trends and Outcomes of Hospitalizations Related to Acute Pancreatitis: Epidemiology From 2001 to 2014 in the United States. Pancreas 2019;48:548-54.

2. Johnson CD, Besselink MG, Carter R. Acute pancreatitis. BMJ 2014;349:g4859.

3. Dixon JM, Chapman RW, Berry AR. Carcinoid tumour of the ampulla of Vater presenting as acute pancreatitis. Gut 1987;28:1296-7.

4. Gao Y, Yu C, Xiang F, et al. Acute pancreatitis as an initial manifestation of parathyroid carcinoma: A case report and literature review. Medicine (Baltimore) 2017;96:e8420.

5. Jang JW, Kim MH, Jeong SU, et al. Clinical characteristics of intraductal papillary mucinous neoplasm manifesting as acute pancreatitis or acute recurrent pancreatitis. J Gastroenterol Hepatol 2013;28:731-8.

6. Li S, Tian B. Acute pancreatitis in patients with pancreatic cancer: Timing of surgery and survival duration. Medicine (Baltimore) 2017;96:e5908.

7. Pitlick MM, Abeykoon JP, Dao LN, et al. Non-Hodgkin lymphoma presenting as acute pancreatitis: A rare occurrence. Clin Case Rep 2019;7:107-9.

8. Tanaka H, Nakazawa T, Yoshida M, et al. Metastasisinduced acute pancreatitis in a patient with small cell carcinoma of the lungs. JOP 2009;10:557-61.

9. Hidalgo M. Pancreatic cancer. Clin Case Rep 2018;7:107-9.

10. Tenner S, Baillie J, DeWitt J, et al. American College of Gastroenterology guideline: management of acute pancreatitis. Am J Gastroenterol 2013;108:1400-15; 1416.

11. Wu D, Lu B, Xue HD, et al. Validation of Modified Determinant-Based Classification of severity for acute pancreatitis in a tertiary teaching hospital. Pancreatology 2019;19:217-23.

12. Yu S, Xiong Y, Xu J, et al. Identification of Dysfunctional Gut Microbiota Through Rectal Swab in Patients with Different Severity of Acute Pancreatitis. Dig Dis Sci 2020;65:3223-37.

13. Cai J, Wu M, Ren J, et al. Evaluation of the Efficiency of the Reticulocyte Hemoglobin Content on Diagnosis 
for Iron Deficiency Anemia in Chinese Adults. Nutrients 2017;9:450.

14. Ko SE, Choi IY, Cha SH, et al. Clinical and radiologic characteristics of pancreatic head carcinoma without main pancreatic duct dilatation: using dual-phase contrastenhanced CT scan. Clin Imaging 2016;40:548-52.

15. Ruan Z, Jiao J, Min D, et al. Multi-modality imaging features distinguish pancreatic carcinoma from massforming chronic pancreatitis of the pancreatic head. Oncol Lett 2018;15:9735-44.

16. Minato Y, Kamisawa T, Tabata T, et al. Pancreatic cancer causing acute pancreatitis: a comparative study with cancer patients without pancreatitis and pancreatitis patients without cancer. J Hepatobiliary Pancreat Sci 2013;20:628-33.

17. Mujica VR, Barkin JS, Go VL. Acute pancreatitis secondary to pancreatic carcinoma. Study Group Participants. Pancreas 2000;21:329-32.

18. Tanasijtchouk T, Vaisbein E, Lachter J, et al. Carcinoma of Papilla Vateri presenting as recurrent acute pancreatitis. Acta Gastroenterol Belg 2004;67:309-10.

19. Mishra SB, Azim A, Mukherjee A. Multiple myeloma presenting as acute pancreatitis. Am J Emerg Med

Cite this article as: Xiong Y, Zhao Y, Han X, Chen G, Windsor J, Wu D, Qian J. Clinical characteristics and outcome of tumor-associated acute pancreatitis: a single-center cohort study. Ann Transl Med 2021;9(8):639. doi: 10.21037/atm-20-7196 2017;35:1385.e1-1385.e2.

20. Kim M, Park JM, Lee SJ, et al. Pancreatic Neuroendocrine Tumor Presenting as Acute Pancreatitis. Korean J Gastroenterol 2018;71:98-102.

21. Stevens KJ, Lisanti C. Pancreas Imaging. StatPearls. Treasure Island (FL): StatPearls Publishing StatPearls Publishing LLC.; 2019.

22. Frampas E, Morla O, Regenet N, et al. A solid pancreatic mass: tumour or inflammation? Diagn Interv Imaging 2013;94:741-55.

23. Cho JH, Choi JS, Hwang ET, et al. Usefulness of scheduled follow-up CT in discharged patients with acute pancreatitis. Pancreatology 2015;15:642-6.

24. Kimura Y, Kikuyama M, Kodama Y. Acute Pancreatitis as a Possible Indicator of Pancreatic Cancer: The Importance of Mass Detection. Intern Med 2015;54:2109-14.

25. Kirkegard J, Gaber C, Lund JL, et al. Acute pancreatitis as an early marker of pancreatic cancer and cancer stage, treatment, and prognosis. Cancer Epidemiol 2020;64:101647.

26. Klein KA, Stephens DH, Welch TJ. CT characteristics of metastatic disease of the pancreas. Radiographics 1998;18:369-78. 